\title{
ANÁLISIS DEL ESCENARIO POSELECTORAL, MÉXICO 2012. \\ Una mirada desde los líderes de opinión de Monterrey y su Área Metropolitana*
}

\author{
Juan Carlos Centeno Maldonado**
}

Recibido: 2014-11-26 - Aprobado por pares: 2015-01-30

Enviado a pares: 2014-11-30 - Aceptado: 2015-02-02

\section{Resumen}

Para la propuesta Análisis del escenario postelectoral, México 2012: una mirada desde los líderes de opinión de Monterrey y su Área Metropolitana, se realizaron 11 entrevistas a profundidad a representantes de los partidos políticos, periodistas, académicos y a representantes de ONG y OSC que se llevaron a un posterior análisis minucioso con el apoyo del programa Nvivo, para que, desde su mirada como líderes de opinión del entorno regional, contribuyeran a responder el objetivo de investigación que nos orienta que es comprender la percepción sobre la cultura política de los líderes de opinión en la entidad en el escenario postelectoral mexicano 2012. Durante el trabajo etnográfico, se profundizó sobre la contribución e impacto de los medios de comunicación tradicionales y las redes sociales al conocimiento del proceso electoral en la ciudadanía.

Palabras clave: cultura política, líderes de opinión, socialización política, medios masivos de comunicación y redes sociales.

* Forma parte de los hallazgos del proyecto de investigación: La cultura política en el escenario postelectoral. Influencia de las elecciones presidenciales y locales de 2012 en la ciudadanía de Nuevo León. Financiado por Programa de Mejoramiento del Profesorado (PROMEP) de la Secretaría de Educación Pública (SEP) de México.

** Recibió los grados: doctor en Política Pública del Instituto Tecnológico y de Estudios Superiores de Monterrey; magíster en Ciencias con Especialidad en Comunicación del Instituto Tecnológico y de Estudios Superiores de Monterrey; sociólogo, en la Universidad Central de Venezuela, y licenciado en Educación, mención Ciencias Sociales, en la Universidad Católica Andrés Bello, Caracas, Venezuela. En la actualidad es profesor de Posgrado e investigador del Centro de Estudios del Derecho a la Información, Gobierno Abierto y Rendición de Cuentas (CEDIGAR), Academia Interamericana de Derechos Humanos de la Facultad de Jurisprudencia, Universidad Autónoma de Coahuila. 


\title{
Post-Electing Scenario Analysis, MÉXICO 2012. A Look from Monterrey and its Metropolitan Area Opinion leaders
}

\begin{abstract}
To carry out the proposal Analysis of Post-Electing Arena, , MÉXICO 2012, A look from Monterrey and its Metropolitan Area Opinion leaders, 11 in-depth interviews were conducted to representatives of political parties, journalists, academics and representatives of NGOs and CSOs, which were submitted to a subsequent detailed analysis supported by Nvivo program, so that from their perspective as leaders of the regional setting opinion, they would contribute to answer the research objective that guides us: to comprehend the perception towards the political culture of the opinion leaders in the state in the postelecting Arena, Mexico 2012. During the ethnographic work, it was emphasized on the contribution and impact of traditional media and social networking to the knowledge of the electing process in citizens.
\end{abstract}

Key words: political culture, opinion leaders, political socialization, mass media and social networking. 


\section{Introducción}

Las pasadas elecciones en México transitaron a través de nuevos factores sociales y políticos. La disputa de los tres partidos predominantes en la contienda electoral (PRI, PRD, PAN) y sus polémicas figuras políticas fueron unas de las variables que propiciaron un incremento en la participación electoral y en el interés sobre la política. Las redes sociales y los medios masivos de comunicación fueron una herramienta indispensable para estar al día con los acontecimientos políticos.

Sumando a lo anterior, la evolución en el uso de los medios electrónicos en el país fue fundamental para un sector de la sociedad, pues, al no estar regulados, no se tiene limitación alguna para el uso y el abuso de sus contenidos.

Las redes sociales en las elecciones, si bien abrieron el conocimiento del quehacer político, sobre todo en los jóvenes, no fueron utilizadas adecuadamente para que orientaran a la comprensión del escenario electoral 2012 en México.

Para los candidatos las redes sociales solo fueron una extensión de la televisión, opinión que contribuyó al inadecuado uso de las mismas tanto por parte de los mismos candidatos, como por los ciudadanos. Según la Asociación Mexicana de Internet (AMICIP)', para la fecha que nos ocupa existían 45.1 millones de usuarios de Internet en México, cifras calculadas por COFETEL al mes de diciembre 2012, con base en información de INEGI $^{2} /$ AMIPCI.

Los medios de comunicación y las redes digitales fueron elementos cruciales de discusión y decisión para el voto de los ciudadanos, pues las dinámicas sociales en razón de la política están evolucionando a medida que madura la democracia. Los procesos electorales competitivos y plurales, y la alternancia política mexicana apenas ocurrieron hace poco más de 13 años. En el año 2000, México inicia una nueva era política a través del triunfo del PAN, luego de más de 70 años del PRI en el gobierno, partido este último que logró establecer redes de poder que aún siguen vigentes en los distintos niveles del sistema político mexicano.

En un modelo democrático que tiene pocos años de desarrollo e implementación, los temas que competen a elecciones, participación ciudadana y cultura política, están íntimamente relacionados. Razón por la cual. Para adentrarnos y analizar el escenario poselectoral en Nuevo León fue preciso comprender las condiciones en las que se presentaron las elecciones, el nivel de cultura política y la intensidad de participación de los electores.

\section{Objetivo general}

Comprender la postura y la influencia de los líderes de opinión en el proceso de construcción de la cultura política en el escenario poselectoral mexicano 2012, los procesos,

\footnotetext{
1 Asociación Mexicana de Internet. Hábitos de los usuarios de Internet en México 2013. (Recuperado en: http:// www.amipci.org.mx/?P=editomultimediafileEMultimedia=348EType=1).

2 Instituto Nacional de Estadística y Geografía
} 
los agentes socializadores y los medios a través de los cuales el nuevoleonés se informa y propicia su participación electoral.

\section{Planteamiento teórico}

En el presente estudio fueron considerados los diversos actores que brindan al ciudadano información política-electoral (representantes de los partidos políticos, periodistas, académicos y movilizadores de base). El estudio consistió en un análisis de su postura y opinión en relación con sus distintos enfoques y áreas de intervención.

Como los autores Buendía y Pino exponen,

[...] la opinión pública surge en la medida que nos relacionamos y que, además, compartimos información y posturas. Para la construcción de lo público, los actores visibles en las comunidades deberán ejercer su liderazgo en espacios de deliberación, debate, concertación, educación, medios de comunicación e industrias culturales (p. 87).

Los líderes de opinión en este estudio indican que forman parte fundamental como medios de socialización de los ciudadanos de Nuevo León; una importante periodista de la entidad expresa:

[...] se ha perdido mucho el diálogo familiar, los valores, el respeto del que está hablando el papá y esté hablando este término político o ese tema eso se ha perdido muchísimo y el medio de comunicación está ahora igualmente que las redes sociales muy abierto. Entonces, este es un punto muy influyente para el auditorio, para la sociedad (20 de marzo, 2013).

Las entrevistas a profundidad son una herramienta útil como medio que ayuda a concretar información sobre el intercambio de opiniones y del quehacer político-electoral en el cual se desarrollan, debido a que las culturas de cada núcleo de la sociedad son permeables en virtud de las influencias sociales y políticas en que se gestan y el momento histórico en que se presentan. Para Manuel Salazar (2002)

[...] las personas, las familias y la comunidad cultural que forman se ubican en un ambiente natural y ecológico, clasifican e interpretan el universo cercano y lejano con lo que conforman la base de su cosmovisión, desarrollan signos y símbolos sociales, establecen principios, valores y normas de convivencia social, natural y política... establecen relaciones económicas; consolidan su identidad cultural y autoestima principalmente a través de sus formas de educación y formación, y se interrelacionan con otras comunidades culturales (p. 2).

El conjunto de relaciones y hábitos de una sociedad es la esencia de su cultura; las figuras públicas generan nuevas formas de entender su realidad, en el caso que sean lo suficientemente influyentes. La interacción con otras culturas también puede llegar a influir, y mucho más en la actualidad, donde nuestra realidad es una conectividad constante con distintos grupos de la sociedad.

El intercambio de ideas, diálogos abiertos y de fácil acceso ha abierto las puertas a nuevas formas de adquirir conocimiento y tienen importante peso en la sociedad 
donde se desenvuelven, reflejan una cara de la cultura, pensamientos, acciones y formas de convivencia de toda una sociedad. "La cultura, una actividad y una dimensión inherente a la persona humana en su sociedad, es particular y dinámica, es comunitaria y universal" (Salazar, 2002, p. 3)

La participación ciudadana dentro de la cultura política es un fenómeno que está diversificado y que se transforma a medida que la misma sociedad la va adecuando a sus necesidades y formas de vida. "Este tipo de participación se acota como ciudadana porque es un proceso o acción que se define y orienta a través de una dimensión, una lógica y unos mecanismos político-sociales específicos" (Espinoza, 2009: p. 4). Entonces, se denota la participación ciudadana en el momento de generar ideas, propuestas, toma de decisiones y cuando se involucra en asuntos públicos que tienen incidencia social. La presencia de la política como práctica en los ciudadanos es indiferente, porque se presenta como ajena, fuera de contexto y excluyente, Murillo (1979) "se manifiesta en un sentimiento de impotencia frente a problemas políticos cada vez más complejos; un sentimiento de que individualmente nada se puede hacer para resolverlos" (p. 38-41). "La sociedad civil no existe en la naturaleza. En la naturaleza existen solamente individuos aislados, independientes unos de los otros" (Bobbio, 2006).

Pasamos de un régimen partidista a una alternancia de partido, elecciones democráticas, instituciones con canales un poco más abiertos a la sociedad, lo cual ha traído como respuesta un interés por participar políticamente, no solo reflejado en el voto u organización de elecciones, sino en organizaciones civiles, partidos políticos, etc. "La demanda de participación en la comunicación pública es un valor permanente en toda sociedad democrática, y hoy aparece de nuevo como consecuencia de la presión y del sobredimensionamiento de una información y una programación crecientemente centralizada, homogeneizadora y banalizada" (Murciano, 2008, p. 3). Sumando a todo ello, los ciudadanos están cada vez más inmersos en los medios masivos de comunicación y las tecnologías de la información, una conexión inmediata con la realidad que se vive, y que impacta verdaderamente en sus acciones y su cultura política.

Los agentes socializadores dentro del desarrollo de una sociedad son diversos e influyen en distintos sectores sociales. Los medios de comunicación se exploran en el presente estudio como generadores de temas, pensamientos y actitudes, sin dejar de lado la fuerte aceleración de las tecnologías de la información. Rojas (2013): "los medios juegan un papel clave como desacreditadores de los partidos políticos. México ha consolidado un sistema mediático que ejerce su rol de guardián del espacio público con una independencia singular" (p. 3).

"Las interacciones en redes sociales plantean nuevas oportunidades y retos para la comunicación interpersonal y, por añadidura, para las dimensiones jurídicas de la libertad de expresión y del derecho a la información" (Rojas, 2013, p.8). Las elecciones del 2012 se desarrollaron en ese contexto de medios de comunicación masivos y redes sociales que, a pesar de haber sido utilizados en menor escala, sí alcanzaron a permear un poco la percepción ciudadana frente a la política y sus actores. 


\section{Metodología}

Se diseñaron y aplicaron entrevistas a profundidad estructuradas. Estas se llevaron a un análisis con el programa de apoyo a la investigación cualitativa y de métodos mixtos llamado NVivo., el cual se aplica para adjuntar entrevistas transcritas y analizar el contenido de las mismas, utilizando herramientas de búsqueda textual y de visualización, para después dar la representación numérica, mostrada en gráficas descriptivas.

Se tomaron como referentes los actores mencionados como personajes que brindan a la ciudadanía de Nuevo León información para la toma de decisiones en el actuar diario y como generadores de una opinión pública estandarizada de gran alcance en un amplio sector de la población. Por ello, se diseñó y aplicó una entrevista estructurada con cinco áreas de estudio.

Luego de haber debatido sobre las categorías de análisis a abordar, se decidieron cinco: 1. agentes socializadores, 2. función de los medios de comunicación, 3. información electoral, 4. participación ciudadana y 5. cultura política. Con la definición de estas categorías, se consideró que se cubrían los cinco aspectos rectores en los que se concentraba el proyecto, el cual tiene como objetivo general comprender la percepción que sobre la cultura política tienen los líderes de opinión en el escenario postelectoral mexicano 2012. Lo anterior en vista de que esta opinión ha sido expuesta a una cantidad importante de información política que puede haber contribuido a la modificación de los patrones cognoscitivos, afectivos, evaluativos y conativos y, por lo tanto, en la determinación de los principales factores que contribuyen a la generación del capital social para la participación ciudadana.

Resuelta la fase de diseño de las categorías de análisis, se redactaron las preguntas de investigación para cada una de ellas, de manera que pudiera obtenerse una guía de entrevista en profundidad estructurada. "Por entrevista definimos, habitualmente, una conversación verbal entre dos o más seres humanos (entrevistador y entrevistado), cuya finalidad es lo que en verdad le otorga el carácter. Es decir en un sentido amplio, la entrevista es una conversación que establecen un interrogador y un interrogado para un propósito expreso (...) es una forma de comunicación interpersonal orientada a la obtención de información sobre un objeto definido" (Sierra, 1998: 281-282). "En las entrevistas estructuradas, el entrevistador realiza su labor con base en una guía de preguntas específicas y se sujeta exclusivamente a esta" (Hernández, Fernández \& Baptista, 2010: 418).

Luego de definido el planteamiento metodológico-instrumental, se pasó a decidir sobre los posibles sujetos a entrevistar. En su momento se llegaron a considerar en el orden de 18 y finalmente se ajustaron a 12 convocados, de los cuales, uno se negó a realizar la entrevista por razones partidistas.

Se terminó por concebir cuatro grupos de actores: 1. académicos, 2. líderes de opinión de medios masivos de comunicación, 3. presidentes estatales de los partidos políticos y 4. movilizadores de base. Todas las entrevistas se realizaron en el orden local, en Monterrey y su Área Metropolitana. 
El contenido de las entrevistas se presenta en las siguientes cinco áreas de estudio; agentes socializadores, función de los medios masivos de comunicación, información electoral, participación ciudadana y cultura política. Con la definición de los entrevistados y de estas categorías, se consideró que se cubrían los cinco aspectos rectores. Posteriormente, se procesaron empleando el software NVivo. Los entrevistados estaban vinculados a las empresas y organizaciones arriba presentadas, con ello se logró, diferenciar los cuatro grupos de actores:
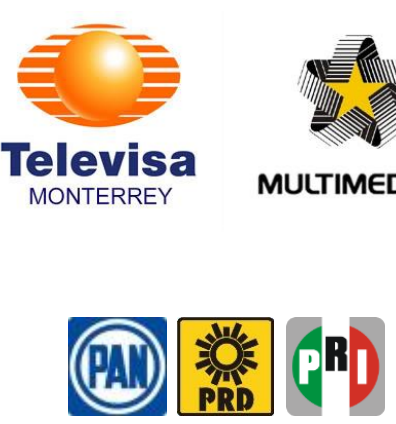

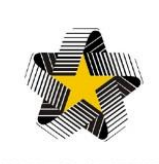

MULTIMEDIOS
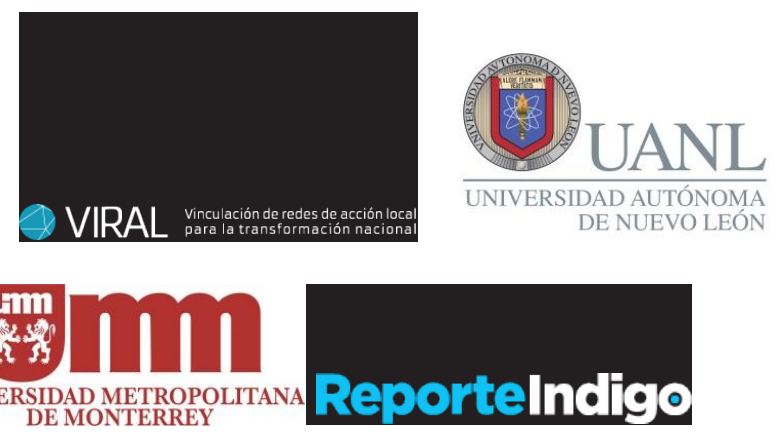

Diagrama 1. Sujetos según vinculación institucional

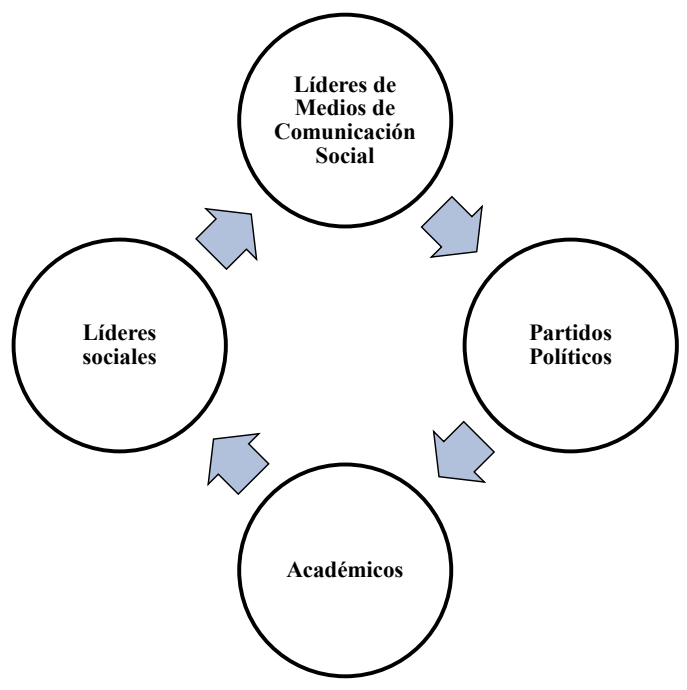

Fuente: elaboración propia

\section{Cultura política como participación ciudadana generada en las elecciones del 2012}

El marco electoral en el cual se efectuaron las elecciones en México en 2012 fue un ejercicio para el aprendizaje político y social del país. Para reafirmar esta idea, es pertinente realizar un recorrido histórico, es decir, un análisis del transcurso en la vida política de 
México. Por lo tanto, no hay que olvidar la presencia del partido hegemónico (Sartori, 2005), Partido Revolucionario Institucional (PRI) como un partido único que gobernó al país por más de 70 años ininterrumpidos, en los cuales estuvieron presentes las prácticas clientelares, corporativistas, antidemocráticas que monopolizaban el poder público y político. El ejercicio del poder se limitaba exclusivamente a un presidencialismo latente, que inhibía por completo el carácter de ciudadano para elegir libremente o concebir una forma de gobierno diferente.

La escuela partidista-electoral que el PRI diseñó a lo largo de sus mandatos generó sus propias reglas del juego político, las cuales fueron adoptadas por todos los actores y partidos. Pero el hecho de que México haya experimentado un gobierno centralizado en una figura presidencial, no quiso, ni quiere decir, que la presión social no tenga como respuesta formar una consolidación democrática.

En México, para el 2012, la preparación por parte del Instituto Federal Electoral, IFE (Ahora INE) de las elecciones ocurre en un momento en el cual aún contaba con un voto de legitimidad, credibilidad y confianza por parte de la sociedad civil. Encargado de organizar y vigilar las elecciones, el Instituto Federal Electoral realiza innovaciones para incentivar al votante que vive en el extranjero a participar mediante el ejercicio del voto desde otras latitudes, lo cual también responde a una urgencia por ganar la credibilidad de los votantes e ingeniar nuevas formas para soportar la poca legitimidad que le quedaba.

Una de las acciones más relevantes en la instrumentación del proceso de liberalización política fue la creación, en 1990, del Instituto Federal Electoral (IFE). Desde su instauración este organismo ha experimentado cambios en sus atribuciones y en su estructura organizacional. Como resultado de la reforma política 2013-2014, el IFE se convirtió en el Instituto Nacional Electoral (INE) (López \& Centeno: 2014).

Las campañas electorales iniciaron en octubre del 2011 y concluyeron con el dictamen y declaración del nuevo Presidente constitucional en septiembre del 2012. Durante toda esta jornada, la tarea de los partidos políticos por agrupar militantes y seguidores se vuelve ardua y termina en un juego de venderse como el más atractivo, como la mejor opción para convencer a los ciudadanos. Ello trae consigo prácticas electorales que no necesariamente son exclusivas de un sistema democrático, como por ejemplo, compra de votos, acarreos el día de la elección, amenazas y condicionamientos a funcionarios públicos, financiamiento de campañas exacerbado, corrupción en las instituciones públicas, entre otros vicios.

Las restricciones que se les presentaron a los partidos políticos que participaron en la contienda de parte del árbitro fueron claras. Sin embargo, la enorme guerra de intereses por parte de los partidos convertía a las campañas y jornadas electorales en una lucha campal que terminaba por afianzar votos o desalentar a los ciudadanos para ejercer su voto.

La información estaba disponible en los medios de comunicación. Bastaba con encender a primera hora de la mañana la televisión para ver temáticas de la arena política. 
La radio, con un grado más de análisis político, ocupabala mayor parte de su espacio con temas de los candidatos. Vía Internet se efectuaba eso que con los medios anteriores no, un dinamismo al momento de análisis, crítica, opinión y difusión por parte de la población informada. Convirtiéndose así en el mejor aliado de los políticos para proyectar sus propuestas y posturas de campaña. Aunque esto implicaba un uso incontrolable de las redes, dado que no estaba bajo ninguna restricción en la Ley Electoral.

Se gestaron todo tipo de discusiones a favor y en contra de los candidatos. El uso de este último medio, en su mayoría entre los jóvenes, los llevó al punto de politizarse o al menos de interesarse por las cuestiones políticas. Pero frente a este interés también vino el hartazgo hacia los actores políticos y las acciones de corrupción que con más frecuencia se dejaban ver por las redes sociales. Esta característica se dio a lo ancho y largo del país. Nuevo León, no fue la excepción. La efervescencia político-electoral se dejó sentir en la población en general, y sobre todo en los jóvenes de la entidad.

Entre las reformas políticas que destacan en el sistema político actual están: 1. las candidaturas ciudadanas a los puestos de elección popular, 2. la presentación de iniciativas de Ley por parte de los ciudadanos en el Congreso, y 3 . la consulta popular para temas de interés nacional. Se modifican 12 artículos de la Constitución y hace adiciones a siete más. Pero, el reto es grande para adecuar a la ciudadanía a estos cambios legales en el devenir electoral y avanzar hacia la constitución de una cultura política. Este tema en Nuevo León no es tan usual en la ciudadanía, como sí lo es entre los especialistas o catedráticos, que lo trabajan como una línea de investigación de la Ciencia Política. La Cultura política se comprende en el contexto de estructuras, elementos, actitudes y agentes socializadores que intervienen en el comportamiento y decisiones de los ciudadanos. La conformación de este concepto abarca aspectos como las creencias, sentimientos, interpretaciones de la política, valores, actitudes ante acontecimientos políticos, culturales y ante sistemas políticos o actores de los mismos.

Para comprender el contexto de la cultura política usaremos la clásica definición de Almond y Verba:

El término cultura política se refiere a orientaciones específicamente políticas, posturas relativas al sistema político y sus diferentes elementos, así como actitudes con relación al rol de uno mismo dentro del sistema. Hablamos de una cultura política del mismo modo que podríamos hablar de una cultura económica o religiosa. Es un conjunto de orientaciones con relación a un sistema especial de objetos y procesos sociales... Cuando hablamos de la cultura política de una sociedad, nos referimos al sistema político que informa los conocimientos, sentimientos y valoraciones de su población... La cultura política de una nación consiste en la particular distribución de las pautas de orientación hacia objetos políticos entre los miembros de dicha nación (pp. 12-13).

Con lo anterior se puede interpretar que la cultura política del neolonés ha evolucionado frente a los acontecimientos sociales a los que se ha enfrentado. Un escenario de violencia al cual se tuvo que adecuar, un crecimiento demográfico, unos flujos migratorios, crisis políticas en los gobiernos, entre muchos aspectos. 
Se producen modificaciones a nivel de la política, toda vez que los medios masivos y sus actores adquieren un rol importante dentro de la sociedad y en las elecciones. En los últimos años ya no se conciben, ni la política ni las campañas electorales, al margen de las redes sociales. Éstas agregan novedosas formas de intervenir y diseñar una opinión pública dentro de una red, blog, página o plataforma virtual, que si bien no tiene efectiva implementación en las decisiones políticas, va adecuando e innovando de manera que estas plataformas permiten recrear las acciones de gobiernos y políticos.

El interés y la fuerte intervención de los medios de comunicación y los medios digitales ha permeado también en la acción del individuo, como lo plantea el estudio de Buendía y Pino: "El acceso directo a los medios permite hacer visible la diversidad de perspectivas, intereses y necesidades de los ciudadanos, y propicia su participación activa en las discusiones y decisiones sobre asuntos de interés público" (2008, p. 94).

La intervención de las redes sociales en las pasadas elecciones representa un punto de partida para la presión política, para el intercambio de ideas, para la generación de plataformas virtuales encadenadas y posiciones políticas, esto es, una comunicación política con nuevas reglas de juego. La comunicación política dentro de la esfera de lo público tiene que estar propiciada por una libre expresión que proviene del interés que cada individuo adquiere y de esta manera compartir y defender posturas frente a otras, como ingredientes para abrir las puertas hacia una democracia que apenas se construye en el país.

Otro tema que secunda a la comunicación política es la libre expresión que como derecho está presente en cada individuo, pero que ha evolucionado en su práctica. Según Nogueira (2003) la libertad de expresión "comprende los conceptos de libertad de opinión e información; consiste en el derecho de toda persona a emitir juicios, ideas y concepciones; buscar, investigar, recibir y difundir el conocimiento de hechos... de relevancia pública ... sin censura ni restricciones preventivas" (p. 5).

Entendida como una participación ciudadana, como la que le pertenece al ciudadano para el ejercicio de la construcción de ciudadanía, el representante del PRD al nivel estatal comenta al respecto de la participación,

"La participación ciudadana es importante y no solo como concepto, ya que tiene conceptos más amplios el plebiscito, participación ciudadana, referéndum, revocación de mandato, el presupuesto participativo, consulta ciudadana, muchas figuras que hacen falta en este país y es necesario para que la gente se empiece a empoderar las decisiones (14 de marzo, 2013).

Por su parte, Giovanni Sartori (2008), importante estudioso de la ciencia política, argumentó en su momento que "la televisión está transformando el sentido de la política y de la democracia porque la personaliza, la representa como un espectáculo, y se basa en apelaciones no racionales y emotivas" (p. 3).

Los medios intervienen entre lo privado y lo público como informadores y creadores de pensamientos que sirven para el elector al momento de decidir su voto y "conocer" al candidato, y así ejercen su derecho al voto. 
"Las imágenes transmitidas por los medios son creadas e interpretadas en culturas políticas particulares, y los periodistas, editorialistas y comentaristas de la radio y la televisión cumplen un papel importante al descodificar estos mensajes. Además, grupos como las iglesias, familias, organizaciones de vecinos y otros gremios, ayudan a descifrar estos códigos y a decidir a quién apoyar en una elección" (De la Torre: 2008, p. 7).

José María Infante, investigador social, comparte su perspectiva sobre los agentes socializadores que intervienen en la vida política y social del nuevoleonés;

Bueno, sin duda, la principal agente socializadora es la familia. La familia como esté ubicada según la cabeza social etcétera, le dará a sus hijos distinta visión de lo que es la política, distinta visión de lo que es el actor en política, distinta visión de lo que es el sistema político etcétera etc., y, bueno, después aparecen los otros agentes socializadores, la educación formal, el sistema de comunicación o los medios de comunicación, y posteriormente otros agentes incluidos los partidos políticos, aunque lamentablemente en México los partidos políticos tienen bastante poca tarea en la socialización es una de las cosas de los tantos defectos de los partidos políticos mexicanos, ipero bueno!... (11 de marzo, 2013).

En México (en nuestro caso Nuevo León) existe aún un núcleo familiar tradicional donde los valores, las cuestiones morales, éticas, entender la realidad e interpretar los asuntos públicos, es una experimentación familiar. Bajo esta estructura se formulan las primeras interpretaciones. La familia funge como primer socializador por su carga emocional y logra forjar la personalidad de sus miembros para posteriormente exponerse a otros agentes socializadores como la escuela, los grupos de amigos, el trabajo, la iglesia, etc.

Lograr una democracia incluyente en todos los sectores sociales se traduce en una construcción y renovación de la cultura política. La cultura es una expresión inseparable de las conductas humanas; por esto es importante integrar un ordenamiento donde todos podamos desarrollarnos con plenitud política, social, económica y particularmente.

\section{Líderes de opinión frente a la cultura nuevoleonesa de las elecciones del 2012}

Ante la concepción de cultura política el catedrático de la UANL Abraham Nuncio comparte la interpretación que le da a la cultura política:

[...] bueno, entiendo que cultura es el sistema de valores que una sociedad tiene; esta es una discusión muy grande, pero lo que entiendo obviamente es que los valores son elementos que se construyen a partir de la elaboración simbólica de la realidad y que todos los elementos que se construyen sean concretos o no, digo son todos materiales; que quede claro: no hay espíritus, pero todos los elementos concretos se organizan en un sistema de valores, la sociedad, el grupo social cuando el homogéneo además le da un valor a los distintos objetos de esa cultura, se le da valor a cosas concretas, digo, como la comida, el oro, ¿qué sé yo?, etcétera o se le da valor a elementos que ya son no tan materialmente tangibles como el poder, las relaciones sociales etc.; entonces cada sociedad organiza un sistema de valores según su propio proceso histórico etc.; esto complica mucho nuestras discusiones, pero esto es lo 
que nosotros tenemos en una sociedad específica y determinada. Entonces, qué es la cultura política, bueno, nuestro sistema de valores que alude al subsistema político de una sociedad, es decir, a la forma de que una sociedad se organiza materialmente. Entonces, bueno aquí vamos a tener que distintas sociedades tendrán obviamente distinta cultura política; en una sociedades, se le da valor a cierto tipo de prácticas, a cierto tipo de relaciones políticas; en otras sociedades se le da valor a otra; aquí quiero decir que también los elementos ideológicos forman parte de los valores y también constituyen los valores; entonces alguna sociedad le dará valor o mucho valor a sistema electoral, mucho valor al voto, otras sociedades le dan valor a otras cosas dentro de la organización política etc. (11 de marzo 2013).

La cultura política en la sociedad neolonesa iba generando los últimos años un clima de apatía por los asuntos políticos, debido a que los ciudadanos no encontraban canales de participación que les dieran sentido y solución a sus demandas o simplemente porque no se sentían partícipes frente a las decisiones del Gobierno. Con las elecciones del año 2012, cambió la forma de ver la política en la entidad. Se implementaron nuevas formas de participar en la entidad, aunque, si bien es cierto se está en un proceso de aprendizaje y de adaptación social a la política. Ante esto un periodista, contribuye con su definición de cultura política: "Son como los modos de actuar, los modos de reaccionar, los modos de pensar alrededor de la participación alrededor de la comunidad y particular mente alrededor de las instituciones públicas" (12 de abril, 2013).

En las pasadas elecciones en Monterrey y su Área Metropolitana, se denotó una activa participación ciudadana debido a las grandes problemáticas sociales derivadas de la inseguridad que se experimenta hasta la actualidad. Las redes sociales que permiten estar en conexión ilimitada intervinieron como medio para generar participación en las asociaciones civiles y ejercer presión sobre el gobierno.

La conectividad entre la sociedad es cada vez más generalizada, teniendo como resultado una interacción interpersonal constante gracias a las tecnologías de información; el ser humano no se concibe sin relacionarse ni comunicarse. Los medios masivos de comunicación en Monterrey y su Área Metropolitana tienen un posicionamiento real que define y moldea gran parte de la cultura política frente a los asuntos públicos de la entidad. Una de las periodistas entrevistadas, expresa su interpretación sobre el nivel de información de los neoloneses frente al pasado proceso electoral:

Sí están enterados, te puedo decir no al cien por ciento, pero un 75, 80 \%, la gente lee, la gente se mete a través de las redes sociales, a través del Internet, pregunta, ve, checa, cuestiona; no está tan ciego o tan indiferente o tan de que no, no me interesa, está atento y está enterado hasta donde llegaron muchas cosas en el pasado proceso electoral (20 de marzo, 2013).

Los medios masivos de comunicación en una ciudad como Monterrey, adquieren un papel primordial a la hora de generar opinión pública y de situar temas en la agenda pública que posteriormente son discutidos en la sociedad. En el mismo sentido el presidente del PAN estatal comparte su opinión sobre los medios de comunicación: 
Tienen una influencia y un impacto directo en las decisiones políticas, lo vemos más en un país como el nuestro que continúa una transición hacia un espíritu de estar no estar bien unidos en democracia, es altamente influenciable lo que los medios hacen o dicen en sus plataformas (20 de marzo, 2013).

El escenario electoral en Monterrey y su Área Metropolitana se vivió bajo condiciones únicas en la historia. Se viene de una alternancia política después de más de 70 años de un partido único, donde las redes de poder se estructuraron fuertemente y donde también podemos decir que se generó una cultura política de separar la figura del político de la ciudadanía, donde no se inmiscuye el ciudadano en temas públicos porque así se ha venido educando y actuando. En cambio, en estas pasadas elecciones, la participación de los electores fue satisfactoria e histórica, y los jóvenes tomaron un papel fundamental. Es aquí donde los medios de comunicación y las redes sociales hicieron su trabajo: inmiscuir al ciudadano en temas políticos, lo que generó un ambiente de participación. Por lo anterior, la líder social Indira Kempis brinda su opinión:

Están enterados creo que más que ningún otro proceso electoral, por primera vez las elecciones del 2012, para empezar tenían uno de los elementos clave que es tecnología y no solamente tecnología en cuestión de nuevos medios de comunicación como son las redes sociales como lo son: facebook, twitter, YouTube, etc., sino también tecnología en presentación de resultados o sea no había encuestadoras hace años, ahora tenemos encuestadoras, se emiten estadísticas, se hace infografía. Antes no se hacía infografía de cuales son los proyectos, los planes los probables actores a la escena, los actores que el probable candidato llamaría a su posible gabinete. Tenemos también información mucho mas sintetizada, ya sabíamos perfectamente donde nació el candidato, casi casi hasta cuando va al baño, antes esa información era intocable era que nadie la conociera mejor. Pero creo que por primera vez también todavía no llegamos a ese proceso de comunicación, si tenemos más información, estamos mejor y tenemos mejores y mayores insumos para tomar una decisión pero todavía no llegamos al punto de que exista la retroalimentación o de que exista un feedback de lo que está sucediendo en la escena política, pero definitivamente creo que fue un proceso al menos que con ese ingrediente de tecnología nos pudo abrir más puertas a la información. Aunque por otro lado eso es un arma de doble filo, porque también habría que cuestionarse ¿qué tiempo de información?, ahorita le decía el ejemplo de casi casi nos dicen cada cuando va al baño pero yo todavía estoy esperando que alguien haga un mapa de relaciones de poder o de ruta de dinero de las campañas políticas por ejemplo y eso no lo conocemos, entonces habría que preguntarse eso (25 de febrero, 2013).

La información presentada en los medios masivos de comunicación y en las redes sociales era instantánea. En la actualidad vivimos en un mundo de comunicación continua; estamos conectados todo el día a la información. Te enteras por la televisión, el periódico, las redes sociales, la radio y sobre todo de la interacción de personas; esa comunicación interpersonal es la que genera más impacto al no solo incluir un mensaje, sino emociones. Los medios de comunicación forjan el canal por el cual el ciudadano puede enterarse de la función de la política, de los acontecimientos públicos, pero deja un vacío de información que finalmente logra desinformar a los electores. Nuevamente la 
movilizadora social Indira Kempis, con respecto a la información que se ha generado en los últimos años como adaptación al medio comenta:

El hecho de que una opinión se pase a la otra a partir de las charlas de familia, de las charlas de cocina, hasta las charlas o debates más intelectuales en las universidades, o en otros espacios sociales. Lamentablemente, en México a partir de el incremento de la violencia y la delincuencia en los espacios públicos dejaron de ser una, quizá otros de los elementos o agentes para socializar la cultura política, lamentablemente por eso, pero yo creo que si han definido también la intervención de esos espacios comunes lo que antes eran los parques, los patios de las iglesias, la calle, los espacios donde la gente se juntaba, interactuaba, intercambiaba opiniones, eran también fundamentales para obtener percepciones, flujos de pensamientos colectivos, ahora ya no tanto, al menos en esta ciudad porque la gente se ha limitado a salir a intercambiar con las demás personas, pero yo creo que eso lo pondría como principal para eso (25 de febrero, 2013).

En la formación de la cultura política se tienen grandes precursores que son los agentes socializadores, entendidos como la familia, la escuela, los grupos de amigos, colectivos, organizaciones civiles, etc. Y estos mismos generaron un movimiento de participación que salió de los medios de comunicación y las redes sociales y se llevó a la calle, exponiendo puntos de vista diversos como hace mucho tiempo no se daba. Respecto al tema el catedrático Abraham Nuncio comenta:

Impactante, más que nunca, influyeron en el proceso, de allí que el rechazo que manifestaban estudiantes de la Ibero, en el movimiento \#YoSoyl32 adquiriera una mayor identidad. En Nuevo León, nunca se había visto a jóvenes participando como participaron, en este proceso; sin organización, ni los jóvenes, ni los adultos pueden avanzar en las soluciones que les convienen a sus intereses. Porque en eso consiste, la ilusión política, en creer que la solución de los problemas de otros, disfrazados de problemas propios, son los que están en juego, y no, son precisamente los que están en juego, lo que no está en juego, son las soluciones a sus propios intereses, de sus problemas entonces es un problema de disfraz que no hemos podido solucionar, las máscaras, las cuales escribió tanto Octavio Paz, pues finalmente, son las que se imponen, y no vemos aquello que se requiere ver, y ello solo lo permite el análisis, la lectura, la discusión y la discusión común, en la asamblea. La asamblea es la que potencia, más que ningún formato de organización, el que los individuos generen ideas, las expongan y que a través del resultado, sea un planteamiento que beneficie a la mayoría (5 de marzo, 2013).

La cultura de participación ciudadana se interpuso de distintas maneras en las elecciones del 2012, inicia con un descontento generalizado por las problemáticas sociales de violencia, crisis económica, desempleo, etc., que aquejan al país (y al Estado). La forma en la que se desarrolla el descontento de los estudiantes de la Universidad Iberoamericana por las violaciones a los derechos en el caso Atenco trastocó al en ese entonces candidato del PRI y ahora presidente del país. Ahí es donde intervienen las redes sociales como canales de información de rápido acceso y de gran impacto; así fue creciendo el movimiento estudiantil llamado \#YoSoy132 en México, que tuvo réplicas en cada Estado de la Republica, y Nuevo León no fue la excepción. Paulatinamente, se fueron integrando 
personas que no solo estudiantes de la Universidad Iberoamericana, sino también de otras instituciones privadas y públicas en el país, así como otros sectores socioeconómicos y culturales convergieron en el movimiento hasta realizar marchas masivas, los intereses de distintas agrupaciones civiles, estudiantiles y políticas encontraron en el movimiento una coyuntura electoral para dar a conocer las diferentes problemáticas a las que se enfrenta el país.

Se tomaban aspectos de ingobernabilidad, de mediatización de televisoras para favorecer al candidato priista; parecía que los medios digitales eran la única manera de tener un panorama amplio y fidedigno de lo que acontecía en el país. Es el contexto donde se desarrolla una nueva ola de participación activa; después de décadas, es allí, en el auge de las redes sociales, donde se da a conocer masivamente el movimiento, que también tuvo sus fracturas, gracias a esa inmediata información a la cual se está expuesto.

\section{Interpretación de los resultados}

El estudio refleja distintos enfoques de los personajes entrevistados, enriquecidos de posturas, opiniones e interpretaciones personales sobre el proceso electoral y la cultura política que se desarrolla. El instrumento de investigación fue de gran alcance para los ejes de la misma: cultura política, función de medios de comunicación, agentes socializadores y participación ciudadana.

A continuación se presentan los resultados de cada área investigada, así como de cada uno de los once integrantes entrevistados, los cuales pertenecen a los cuatro ejes (periodistas, catedráticos, movilizadores de base y representantes de partido), que son determinados como importantes agentes socializadores para la sociedad de Monterrey y su Área Metropolitana en las elecciones del 2012. Se logra comprender las posturas de cada líder de opinión ante cada eje de investigación.

Tabla 1. Relación porcentual del discurso de los sujetos según las categorías de análisis del guion de entrevistas

\begin{tabular}{|c|c|c|c|c|c|c|}
\hline \multicolumn{2}{|c|}{$\begin{array}{c}\text { Agentes } \\
\text { Socializadores }\end{array}$} & $\begin{array}{c}\text { Función de } \\
\text { Medios de } \\
\text { Comunica- } \\
\text { ción }\end{array}$ & $\begin{array}{c}\text { Información } \\
\text { Electoral }\end{array}$ & $\begin{array}{c}\text { Participación } \\
\text { Ciudadana }\end{array}$ & $\begin{array}{c}\text { Cultura Po- } \\
\text { lítica }\end{array}$ & Total \\
\hline Sujeto 1 & $27.56 \%$ & $20.79 \%$ & $7.74 \%$ & $42.81 \%$ & $1.10 \%$ & $100 \%$ \\
\hline Sujeto 2 & $28.04 \%$ & $5.75 \%$ & $1.17 \%$ & $29.58 \%$ & $35.46 \%$ & $100 \%$ \\
\hline Sujeto 3 & $29.55 \%$ & $27.49 \%$ & $16.59 \%$ & $17.55 \%$ & $8.82 \%$ & $100 \%$ \\
\hline Sujeto 4 & $23.70 \%$ & $10.45 \%$ & $12.91 \%$ & $36.82 \%$ & $16.12 \%$ & $100 \%$ \\
\hline Sujeto 5 & $20.70 \%$ & $23.95 \%$ & $13.52 \%$ & $23.97 \%$ & $17.86 \%$ & $100 \%$ \\
\hline Sujeto 6 & $20.67 \%$ & $19.44 \%$ & $5.86 \%$ & $29.88 \%$ & $24.14 \%$ & $100 \%$ \\
\hline Sujeto 7 & $24.56 \%$ & $20.23 \%$ & $8.16 \%$ & $21.10 \%$ & $25.95 \%$ & $100 \%$ \\
\hline
\end{tabular}




\begin{tabular}{|c|c|c|c|c|c|c|}
\hline \multicolumn{2}{|c|}{$\begin{array}{c}\text { Agentes } \\
\text { Socializadores }\end{array}$} & $\begin{array}{c}\text { Función de } \\
\text { Medios de } \\
\text { Comunica- } \\
\text { ción }\end{array}$ & $\begin{array}{c}\text { Información } \\
\text { Electoral }\end{array}$ & $\begin{array}{c}\text { Participación } \\
\text { Ciudadana }\end{array}$ & $\begin{array}{c}\text { Cultura Po- } \\
\text { lítica }\end{array}$ & Total \\
\hline Sujeto 8 & $25.99 \%$ & $33.86 \%$ & $14.72 \%$ & $12.10 \%$ & $13.33 \%$ & $100 \%$ \\
\hline Sujeto 9 & $17.17 \%$ & $16.42 \%$ & $10.10 \%$ & $21.20 \%$ & $35.10 \%$ & $100 \%$ \\
\hline Sujeto 10 & $18.88 \%$ & $19.62 \%$ & $8.35 \%$ & $38.31 \%$ & $14.85 \%$ & $100 \%$ \\
\hline Sujeto 11 & $19.99 \%$ & $14.25 \%$ & $9.08 \%$ & $27.08 \%$ & $29.60 \%$ & $100 \%$ \\
\hline
\end{tabular}

Fuente: elaboración propia, a través de la aplicación del software NVivo

Al evaluar el discurso de cada uno de los cuatro grupos de actores (líderes de opinión, líderes políticos, movilizadores de base y especialistas) en el contexto electoral y poselectoral en el cual estuvieron inmersos, se encontró que los menores porcentajes en el discurso de los entrevistados le corresponde a la información electoral, ítem que tuvo el segundo porcentaje más bajo de todo el análisis, con $1.17 \%$. Este resultado permite suponer que el tema referente a la información electoral está en el último lugar de su agenda pública. Entonces, se puede interpretar que a mayor bombardeo de información a través de los medios masivos de comunicación se obtiene un menor impacto en la comunidad como para suponer que sea el tema principal que circunde en la sociedad.

Quienes usan más el tema de la información electoral son los líderes de opinión, un público especializado, (aunque en bajos porcentajes de la tabla 1), ya que ellos son personajes importantes como formadores de opinión en los ciudadanos de Monterrey y que están muy inmersos dentro del seguimiento de las elecciones.

Sin embargo, el tema de participación ciudadana tiene gran impacto en las figuras partidistas del Estado (políticos), representado en el porcentaje más amplio con 42.81 \% del contenido de sus respuestas. Es entendible que como líderes políticos lleven a la práctica y comprendan que el crecimiento de un partido u organización se debe a la participación activa de los ciudadanos. Es una concepción totalmente politizada la que le atribuyen los políticos a la participación ciudadana y su relación con las instituciones de Gobierno.

Se logra comprender una característica de los movilizadores de base, cuyo interés se centra en el tema de la cultura política, comprendida esta en el contexto de estructurar y analizar los agentes socializadores que intervienen en el comportamiento, actitudes y decisiones de los ciudadanos.

El análisis permitió determinar un interés claro por cada actor en el área en la cual desarrolla su ejercicio profesional y sus intereses académicos, los cuales fueron formulando y exponiendo durante su entrevista. Los líderes de opinión se inclinan por la información electoral, y función de medios masivos de comunicación, donde toman mayor injerencia y conocimiento del tema. Los líderes políticos o figuras políticas, claramente enmarcan su discurso y acción en el tema de la participación ciudadana, tomando como base la organización partidista a la cual pertenecen o representan. 
Los movilizadores de base, mayormente inclinan su mensaje a la participación ciudadana, aunque también tienen redefinida la acción de la cultura política en su campo de acción como factor para desarrollar una participación ciudadana eficaz que aún no está del todo madura dentro de la sociedad neolonesa.

Por último, los especialistas o catedráticos tienen una vinculación con diversas áreas, empezando por la más predominante que es la cultura política. Coinciden la totalidad de entrevistados, primeramente, sobre este tema, teniendo las mayores cargas porcentuales, En segundo lugar está el tema de la participación ciudadana.

Tabla 2. Correlación de sujetos y tematización discursiva

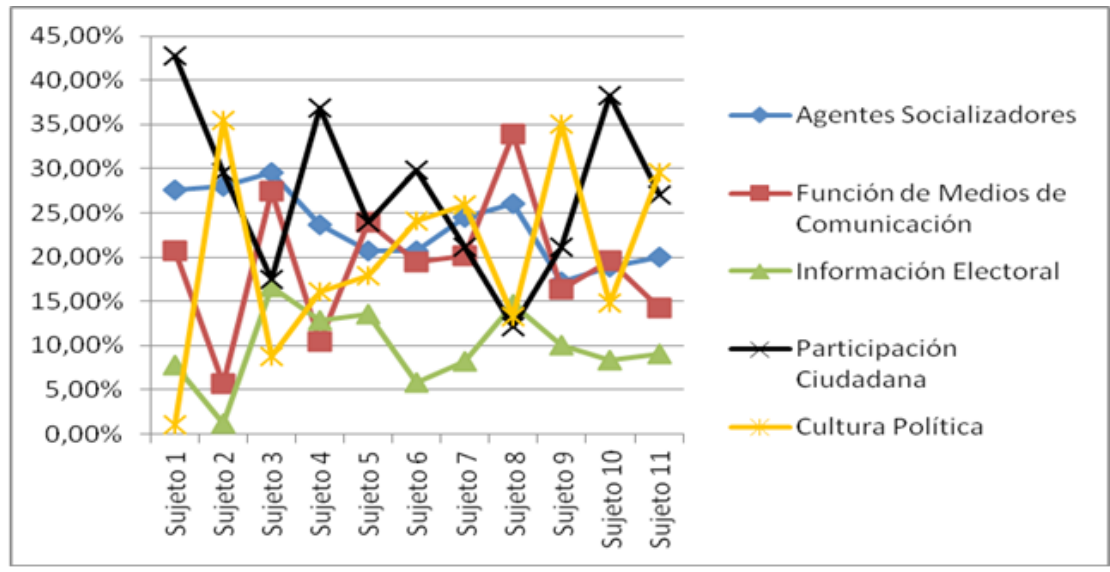

Fuente: elaboración propia, a través de la aplicación del software NVivo

\section{Conclusiones}

La información electoral ocupa el último escaño en el tema y en la práctica de los ciudadanos (en cuanto a democracia mínima). Ello indica el bajo interés en los asuntos públicos y de gobierno, el pensar que la política es de quien la práctica y no de quien la construye.

El hecho de que que no exista, como tema preponderante la información electoral en los entrevistados dentro de la sociedad neolonesa en un estudio del escenario postelectoral, hace suponer que no existe un manejo eficiente de la información, las estrategias y los medios, que logre impactar en la mayoría de actores y, por ende, no se logra tener impacto en la ciudadanía, en los electores.

Lo que sí se puede afirmar a través de los resultados es que la categoría cultura política la integran todos los actores entrevistados, quienes pertenecen a instituciones completamente distintas. El tema de la cultura política, como ya se planteó anteriormente, es la manera de conocer los intereses que llevan a la toma de decisiones de las personas dentro de una entidad como Nuevo León.

Los medios masivos de comunicación intervienen como grandes canales de socialización entre las personas pero no logran politizar ni hacer más incluyente al ciudadano en los 
procesos políticos. El tema de los medios masivos de comunicación se trata solo en esa esfera de los comunicólogos o periodistas, sin impactar verdaderamente a los movilizadores de base, ni a los políticos.

La lectura que se puede dar al estudio y análisis del discurso de cada uno de los líderes de opinión entrevistados nos brinda un panorama claro de cómo se vivieron las elecciones en Nuevo León, de las características culturales de la sociedad y de la clase política en la que se está inmerso. La importancia de conocer las opiniones de diversos actores políticos de la entidad dio unas radiografías de las prácticas ciudadanas como formas de participación que han evolucionado a través de los medios masivos, redes digitales, acciones de gobierno y culturales.

La valoración que da cada uno de los actores a los medios de comunicación como formadores de opinión y como medios de socialización influyentes a las redes sociales en las elecciones es solo el comienzo de una democracia más participativa dentro de la esfera pública. Convierte al ciudadano en un actor altamente sofisticado para poder participar de la manera más efectiva en los procesos políticos y adquirir mayor presencia en la práctica política.

Se resaltó la importancia de los medios masivos y de sus periodistas como destacados actores generadores de componentes valorativos de la cultura política en los ciudadanos. Los medios masivos de comunicación adquieren una presencia cada vez mayor entre de los ciudadanos.

\section{Referencias}

Almond, G. A., y Verba, S.: The Civic Culture. Political Attitudes and Democracy in Five Nation.

ASOCIACIÓN MEXICANA DE INTERNET. Hábitos de los Usuarios de Internet en México 2013. (En línea).

Recuperado en: http://www.amipci.org.mx/?P=editomultimediafileEMultimedia=348EType =1

Buendía y Pino (2008). Radio local, opinión pública y participación ciudadana. En Signo y Pensamiento

52 · volumen XXVII, pp. 84-96. (Disponible en: http://www.javeriana.edu.co/signoyp/coleccion.htm)

Bobbio, Matteucci y Pasquino, G (2005), Diccionario de política, México, Siglo XXI.

Bobbio, N. (2006) Estado, Gobierno y Sociedad Civil. México: FCE.

http://www.alice-comunicacionpolitica.com/abrir-ponencia. php?f=426-F5236ba7b4261379318395 ponencia-1.pdf

De La Torre, C. (2008) Medios, Representación y Calidad de la democracia en américa latina. Debates en Sociología. Vol. 33 pp. 31-50.

Duverger, M. (2012). Los Partidos Políticos. México: FCE.

Espino, G. (2011). La transformación de la comunicación política en las campañas presidenciales de México. Convergencia: Revista de Ciencias Sociales, Vol. 18, pp. 59-86.

Espinoza, M. (2009). La Participación Ciudadana Como una Relación Socio Estatal Acotada por la Concepción de Democracia y Ciudadanía. Volumen 5, número 10. pp. 71 109. 
Hernández, R; Fernández, C y Baptista, P. (2014). Metodología de la Investigación (6. a ed.). México: McGraw Hill.

López \& Centeno (2014). De la Reforma a la Contra Reforma. 25 Años de Cambios en el Sistema Electoral Mexicano. En: La materia electoral en América Latina. Argentina. Facultad de Derecho de la Universidad de la Plata (UNLP).

Michels, R. (2003). Los partidos políticos I: un estudio sociológico de las tendencias oligárquicas de la democracia moderna. Argentina: Amorrortu.

Michels, R. (2003). Los partidos políticos II: un estudio sociológico de las tendencias oligárquicas de la democracia moderna. Argentina: Amorrortu.

Moodie E Studdert-Kennedy. (1975). Opiniones, públicos y grupos de presión. México: Fondo de Cultura Económica.

Murciano, M. (2008) Democracia, cultura y tecnología: Ejes de las políticas de comunicación. Revista Trimestral "Chasqui". Pp. 40-45.

Murillo, F. (1979), Estudios de sociología política, Madrid, Tecnos.

Nogueira, H. (2003). El derecho a la información en el ámbito del derecho constitucional comparado en Iberoamérica y Estados Unidos. En Carpizo, J. y Carbonell, M. (Coords.), Derecho a la información y derechos humanos. México: Porrúa - UNAM-IIJ.

Prieto, J. (2013). Libertad de expresión, Internet y comunicación política. Cotidiano - Revista de la Realidad Mexicana. Vol. 28, pp. 79-94.

Romero, D. (2006). El concepto de cultura política en ciencia política y sus implicaciones para la historia. (En línea) Recuperado en: http://www.ahistcon.org/docs/ayer/ayer61/61-10.pdf

Rubio Núñez, R. (s/f). Los grupos de presión. Departamento de Derecho, Universidad Complutense de Madrid. (Disponible en: http://www.rafarubio.es/wp-content/uploads/GRUPOSDEPRESION.pdf)

Salazar, M. (2002). Hacia una democracia inclusiva construcción de una cultura política para todos. Revista Cultura de Guatemala, Vol. 23, pp. 193-200.

Sartori, G. (2005). Partidos y Sistemas de Partidos. Madrid: Alianza.

Sierra, F. (1998). Función y sentido de la entrevista cualitativa en investigación social. En J. Galindo Cáceres, Técnicas de investigación en sociedad, cultura y comunicación, pp. 277 - 345. México: Pearson.

\section{Fuentes Electrónicas:}

http://info4.juridicas.unam.mx

http://www.ife.org.mx

http://www.diputados.gob.mx

http://www.senado.gob.mx 